\title{
Game Form Misconceptions Do Not Explain the Endowment Effect
}

\author{
Björn Bartling \\ Florian Engl \\ Roberto A. Weber
}

CESIFO WORKING PAPER NO. 5094

CATEgORY 13: BeHAVIOURAL ECONOMICS

NOVEMBER 2014

An electronic version of the paper may be downloaded

- from the SSRN website:

- from the RePEc website:

- from the CESifo website:

WWW.SSRN.com

www.RePEc.org

www.CESifo-group.org/wp

\section{CESifo}




\title{
Game Form Misconceptions Do Not Explain the Endowment Effect
}

\begin{abstract}
We test the claim that game form misconception among subjects making choices through the Becker-DeGroot-Marschak (BDM) value elicitation procedure provides an explanation for the endowment effect, as suggested by Cason and Plott (forthcoming). We employ a design that allows us to clearly identify whether subjects comprehend the incentive properties of a pricelist version of the BDM procedure. We find a robust endowment effect, even among those subjects whose elicited valuations for a known monetary value and whose ability to calculate the payoffs resulting from their choices indicate no misconception of the task. We conclude that game form misconceptions alone are unlikely to account for behavioral patterns like the endowment effect.
\end{abstract}

JEL-Code: C910, D030.

Keywords: endowment effect, game form misconception, BDM mechanism, experimental methods, replicable audio files of instructions.

\author{
Björn Bartling* \\ Department of Economics \\ University of Zurich \\ Blümlisalpstrasse 10 \\ Switzerland - 8006 Zurich \\ bjoern.bartling@econ.uzh.ch
}

\author{
Roberto A. Weber \\ Department of Economics \\ University of Zurich \\ Blümlisalpstrasse 10 \\ Switzerland - 8006 Zurich \\ roberto.weber@econ.uzh.ch
}

${ }^{*}$ corresponding author

November 14, 2014

We thank participants in the Reading Group in Experimental Economics at the University of Zurich for valuable discussion. 


\section{Introduction}

A recent article by Cason and Plott (forthcoming, Journal of Political Economy) argues for caution in drawing inferences about non-standard preferences from choice data using experimental value elicitation procedures, such as the mechanism introduced by Becker, DeGroot and Marschak (1964, henceforth, BDM). This argument raises significant challenges to much of the experimental literature, including the vast literature on the endowment effect-i.e., the tendency for subjects endowed with an object to state higher valuation for that object than subjects not endowed with it—which is one of the most widely studied phenomena in behavioral economics (see Kahneman, Knetsch and Thaler, 1991; Ericson and Fuster, 2014).

Cason and Plott support their argument with evidence that a systematic bias in subjects' stated valuations for an item with a known dollar value is reflective of subjects' misunderstanding of the game form-that is, subjects systematically fail to understand the incentive properties of the BDM mechanism and therefore over-report their valuation. Specifically, Cason and Plott conduct a classroom experiment in which they endow subjects with a card that is redeemable from the experimenter for $\$ 2$, and allow subjects to state sales price offers through the BDM procedure. A random posted price between $\$ 0$ and $\$ 8$ is generated, and a subject sells his card to the experimenter only if this posted price exceeds the subjects' stated offer price. Using this design, Cason and Plott find that a large majority of subjects (83 percent) do not select offers within 5 cents of the dominant strategy offer price of $\$ 2$. This frequency of misconceived subjects decreases, to 69 percent, with feedback and repetition. Moreover, subjects' offers are biased upward, and are also influenced by the upper range of the distribution from which the posted prices are drawn. From this evidence, Cason and Plott argue that studies in which researchers attempt to make inferences about preferences from experiments using the BDM elicitation procedure should be taken with caution. In their words, "the failure of game form recognition can masquerade as support for the theory of framing, as preferences constructed from reference points."

The possibility that game form misconceptions may account for behavior inconsistent with standard models of choice in some experiments is intriguing-indeed, this seems to be case in Cason and Plott's experiment. However, what is missing from the literature-including from Cason and Plott's work-is an attempt to carefully identify whether or not such misconceptions actually do account for behavioral patterns often interpreted as framing. That is, the fact that 
Cason and Plott conduct an experiment in which subjects seem not to understand the incentive properties of the BDM mechanism does not constitute clear evidence that other attempts to identify preferences using similar procedures are similarly unreliable.

Our paper provides a more direct study of the relationship between subject misconceptions regarding the BDM procedure and tests of non-standard preferences such as the endowment effect. That is, to test whether subjects' misunderstanding of the incentive properties of the BDM mechanism can actually account for behavior that looks like the endowment effect, we not only follow the recommendation that "experimental procedures should be designed to avoid "subject misconceptions"' (Plott and Zeiler, 2005), but go further and focus the analysis on those subjects for whom we have strong evidence that there is no misconception. If, when studying subjects who do not hold misconceptions about the incentive properties of the BDM mechanism one also finds no evidence of framing effects, then this constitutes more direct support for Cason and Plott's suggestion that the source of framing effects lies in subject misconceptions regarding the BDM procedure. However, if subject misconceptions about the BDM procedure are absent, but subjects nevertheless exhibit behavior consistent with an influence of framing on preferences, then we can exclude that the observed behavior is driven by mistakes in understanding the incentive properties of the BDM.

To address this open question, we conduct an experiment in which we employ choice procedures designed to reduce subject misconceptions regarding the incentive properties of the $\mathrm{BDM}$, relative to the way in which this procedure was implemented in Cason and Plott's experiment. Specifically, we employ a price-list representation of the BDM procedure, in which subjects are presented with a series of prices and asked, for each price, whether they are willing to trade at that price (Kahneman, Knetsch and Thaler, 1990; Murphy, et al., 2010). Subjects are restricted to switch from buying to not buying or from not selling to selling, at only one price. For each possible price, we present subjects with the payoff consequences of the two possible choices. Hence, unlike in Cason and Plott's study, we provide subjects with more salient and accessible information regarding the payoff implications of their choices.

Furthermore, before subjects can finalize their choices, we also require that they calculate the actual payoff consequences for each of the choices that they have made. More precisely, for every possible price that might realize in the experiment, we ask a subject to tell us what his or her payoff would be if that price were randomly drawn, based on the precise choices made by that subject. We provide subjects with a monetary incentive to calculate earnings correctly on the 
first attempt, and only allow their choice to be implemented once they have correctly entered all payoff calculations. Hence, all subjects, at the time of implementing a choice, have correctly calculated all of the payoff consequences from their choices. Moreover, we can identify those subjects who entered such calculations correctly on the very first attempt.

In a first part of our experiment, we conduct a study similar to that of Cason and Plott. Specifically, we elicit buying and selling prices for a card worth precisely 8.50 Swiss francs $(\mathrm{CHF})$ from the experimenter. Our price-list version of the BDM creates incentives such that buyers should switch from buying to not buying and sellers should switch from selling to not selling between the prices of 8 and $9 \mathrm{CHF}$ (our price list was restricted to integer prices). We observe a large majority of subjects, 70 percent, in this first part of the experiment making these optimal choices. Moreover, a majority of subjects also calculate all of the payoff consequences of their choices correctly on the first attempt. Unlike in Cason and Plott's experiment, we observe no statistically significant tendency to overstate selling prices by sellers, nor do we observe a tendency to understate buying prices by buyers. Hence, game form misconception, as identified by Cason and Plott, while still potentially present among a minority of subjects, appears lower than that obtained Cason and Plott's design and it does not appear to lead to systematic mistakes in our data.

In a second part of the experiment, we conduct a standard endowment effect study, in which subjects are either endowed with a box of chocolates and state minimum selling price offers, or are not endowed with but can bid to buy the same box of chocolates. Here, despite the fact that the first part of our experiment demonstrated low levels of subject misconception of the BDM mechanism, we find strong evidence of an endowment effect. Subjects endowed with the box of chocolates offer prices that are roughly twice as high as the bids made by subjects deciding whether to acquire the same box of chocolates. Hence, our design shows that a large endowment effect obtains in a population with relatively low levels of misconception.

Moreover, our procedure allows us to go even further in testing whether subjects who are not misconceived also demonstrate no endowment effect. Specifically, we are able to identify a subset of subjects who satisfy three conditions that are likely to mean they have no miscomprehension of the BDM mechanism or its payoff consequences. First, following the identification procedure in Cason and Plott, we consider only subjects who bid optimally in the first task, with known value. Second, we further eliminate any subjects who did not enter the payoff calculations entirely correctly on their first attempt in the first task. Finally, we also 
eliminate subjects who did not enter the payoff calculations correctly in the second task, when bidding or offering prices for the box of chocolates, on their first attempt. Hence, what remains are subjects who i) stated optimal prices in the BDM with known value, ii) calculated all payoff consequences correctly in the BDM with known value on their first attempt, and iii) calculated all payoff consequences in the BDM for the box of chocolates on their first attempt. We believe these subjects are very unlikely to have misconceptions about the BDM game form. Looking only at these subjects, we nevertheless replicate a strong endowment effect, comparable in magnitude to the one we identify in the population as a whole.

Before proceeding to our design and results, it is important to note that we do not attempt to provide a comprehensively rigorous test of whether the endowment effect represents true valuation of the commodity, or whether it results from some other form of behavioral anomaly, misperception of the value of the commodity, or alternative sources of utility or disutility (cf. Plott and Zeiler, 2005 and 2007; Weaver and Frederick, 2012). Instead, our simpler goal is to test whether the possibility that subjects fail to understand the mechanics and incentive properties of the BDM procedure can account for gaps in willingness-to-pay versus willingness-to-accept that might be interpreted as evidence of the endowment effect. Our findings show that such gaps clearly hold in a sample of subjects for whom it is very unlikely that there is any such misconception.

\section{Experimental Design}

Subjects participated in two decision tasks, presented as Parts I and II of the experiment. Part I consisted of a BDM value elicitation choice task for an object with fixed and known value. Part II consisted of an identical choice task for a good with heterogeneous and unobservable value. Subjects were informed that either Part I or Part II would count for their earnings in the study, but not both, and that the decisions in one part had no consequences for the respective other part.

At the beginning of the study, subjects were randomized to be in the role of either buyer or seller. Randomization took place on the session level; that is, in a given session all subjects were either buyers or sellers. At the outset of the study, subjects were informed that they received an initial endowment of CHF 25, as a show-up fee. 


\subsection{Part I}

Subjects in a buyer session could buy a "card" from the experimenter. The card was a small piece of paper located at the subject's computer terminal, which stated, "This card is worth 8.50 CHF." If a subject bought the card, he or she could redeem it for $8.50 \mathrm{CHF}$ from the experimenter at the end of the study. The BDM mechanism was used to elicit the highest price a subject was willing to pay to buy the card. At the end of the study, the computer drew an individually randomized price between 0 and $20 \mathrm{CHF}$, in increments of $1 \mathrm{CHF}$. Each subject decided, for all possible 21 prices, whether or not to buy the card at that price. If a subject bought the card, he or she could redeem it for $8.50 \mathrm{CHF}$, but had to pay the price out of the initial endowment of $25 \mathrm{CHF}$. If the subject did not buy the card, he or she could not redeem it, but did not pay the randomly drawn price. Subjects entered their choices in a table in which each row corresponds to a possible price, by clicking either on a box stating "I buy at this price" or on a box stating "I do not buy at this price." 2 Prices were ordered from 0 CHF (top row) to $20 \mathrm{CHF}$ (bottom row). Subjects were informed that they should indicate the maximum price they were willing to pay for the card, and that they should therefore only have one price at which they switch from buying to not buying, as their decisions would otherwise be inconsistent. ${ }^{3}$

Subjects in a seller session were endowed with the card-the instructions explicitly stated "The card is yours, you own it."- but had the option to sell it to the experimenter. They had to decide, for each possible price, whether or not to sell the card at that price. If they sold the card, they could not redeem it for $8.50 \mathrm{CHF}$, but received the randomly drawn price, in addition to their initial 25 CHF. If they did not sell the card, they could redeem it for $8.5 \mathrm{CHF}$, in addition to their initial $25 \mathrm{CHF}$, but did not receive the price. Each seller indicated his or her choice in a table that was equivalent to the one presented to buyers. For each of the 21 possible prices, a seller had to click either on a box stating "I sell at this price" or on a box stating "I do not sell at this price." As with buyers, unique switching points were enforced.

Clearly, with an induced value of $8.50 \mathrm{CHF}$, payoff-maximizing subjects should buy the card for prices of at most $8 \mathrm{CHF}$ and sell it for prices of $9 \mathrm{CHF}$ or higher. Hence, following the logic in Cason and Plott, a buyer who switches from buying the card at a price of $8 \mathrm{CHF}$ to not buying at a price of $9 \mathrm{CHF}$ or a seller who switches from not selling at a price of $8 \mathrm{CHF}$ to selling at a price of $9 \mathrm{CHF}$ is unlikely to suffer from game form misconception.

\footnotetext{
${ }^{2}$ Instructions and choice interfaces are provided in the online appendix.

${ }^{3}$ If a subject indicated more than one switching point, the computer would not allow the subject to proceed.
} 
We also included an additional test of whether subjects understood the BDM mechanism. After subjects made their choices for each price and clicked an "OK" button to proceed, subjects had to enter the exact payoffs that would result for each of the possible 21 prices, given the subject's choice (buy/not buy or sell/not sell) at that price. At that point, subjects also had the option to change any of their previous buying or selling decisions for any of the 21 possible prices, with the requirement of continued consistency. Once subjects were ready to proceed with their choice, the computer verified whether they had calculated all of the resulting payoffs correctly. If a subject entered all 21 payoffs correctly on the first attempt, given his or her final choices, the subject earned an additional 2 CHF. If the subject entered any of the calculated payoffs incorrectly, the computer would return to the calculation screen, from which subjects could also change their choices. The computer allowed a subject to proceed only once he or she entered all payoffs correctly.

\subsection{Part II}

Part II of the study was identical to Part I except for exactly one difference: subjects did not trade an object of induced value (a card worth $8.50 \mathrm{CHF}$ ) but a box of chocolates. ${ }^{4}$ The box of chocolates was purchased form a well-known Swiss confectionary at a retail price of $17 \mathrm{CHF}$, but subjects were not informed about this price. As in Part I subjects in a buyer session could buy the box of chocolates from the experimenter. A box was located at each subject's computer terminal. We used exactly the same BDM mechanism as in Part I to elicit a subject's maximum willingness to pay, with random prices between 0 and $20 \mathrm{CHF}$ (individually drawn at the end of the study), in increments of $1 \mathrm{CHF}$. The screen that was employed to elicit buying decisions for each possible price corresponded exactly to the screen used in Part I. If a subject bought the box, the subject could take it home, but had to pay the price out of the initial endowment $25 \mathrm{CHF}$ endowment. If a subject did not buy the box, the subject could not take it home, but did not have to pay the drawn price. A unique switching point was enforced, as in Part I.

Subjects in a seller session were endowed with the box of chocolates but had the option to sell it to the experimenter. As in Part I subjects had to decide, for each possible price, whether or not to sell the box of chocolate at prices between 0 and 20 CHF. If a subject sold the box, he or

\footnotetext{
${ }^{4}$ We did not counterbalance the order of the two tasks. Cason and Plott find that subject misconception about the BDM decreases with experience. Therefore, by having the task that we use to measure misconception first, and the task in which we principally care about whether there is misconception second, our classification of subject comprehension in the latter task is conservative.
} 
she could not take it home, but received the randomly drawn price, in addition to the initial 25 CHF. If a subject did not sell the box, he or she could take it home, in addition to the initial 25 CHF, but did not receive the price. The interface that was employed to elicit selling decisions for each possible price corresponded exactly to the screen used in Part I. A unique switching point was enforced.

As with Part I, subjects again had to calculate all possible realized payoffs based on their specific choices, before proceeding. Subjects now had to enter their resulting monetary earnings and also whether they would own or not own the box of chocolates, for each of the possible 21 prices, given their choices at that price. At that point, subjects had the option to change any of their previous buying or selling decisions, and they earned an additional 2 CHF if they entered all 21 potentially resulting payoffs correctly on the first attempt. The computer allowed a subject to proceed only once he or she entered all payoffs correctly.

An important feature of the experimental design is that it allows a within-subject comparison of the decisions taken in Parts I and II. The use of an item of induced value in Part I, together with the incentivized calculation of the resulting payoffs, allow us to identify which subjects understand the incentive properties of the BDM mechanism. Subjects who make payoffmaximizing choices in Part I and calculate all of their payoffs correctly presumably hold no misconception about the BDM procedure. Hence for such subjects, we can assume that elicited valuations in Part II for the box of chocolate are not biased by game form misconception.

\subsection{Additional Measurements}

After subjects completed Part II, we administered two measures of cognitive ability: a cognitive reflection test (Frederic, 2005) and a computerized 12-item Raven Progressive Matrices test (Raven et al., 2007). Subjects received additional 0.50 CHF for each correctly solved puzzle in the Raven test.

\subsection{Methodological Note: Highly Replicable Laboratory Environment}

Our design also employs a novel procedure that allows high degrees of replicability across experimental sessions and, in principle, across experimental laboratories. Specifically, subjects received instructions both through printed instructions at their desk and through an audio 
recording played via loudspeaker in the laboratory. ${ }^{5}$ Hence, aside from the initial greeting of subjects before they are assigned to desks, and the responses to individual questions, all of the key elements of our laboratory environment can be reliably replicated across sessions in our laboratory or elsewhere. Indeed, a researcher need only distribute paper instructions, play the audio files, and start the experimental software to conduct a virtually identical session to the ones in this study. ${ }^{6}$ We consider this enhanced replicability important for at least two reasons. First, the use of pre-recorded audio files to deliver instructions ensures that these are delivered in exactly the same manner across multiple sessions and by a speaker unaware of the experimental hypotheses. Second, it lowers the barriers to direct replication, since a researcher at any point in the future has a clearer understanding of the precise laboratory environment and the ability to replicate it more closely.

\subsection{Information on Sessions, Subjects, and Earnings}

We conducted four sessions on two consecutive days in November 2014, with 140 subjects in total. On each day, we conducted one buyer session and one seller session. The order of the buyer and seller sessions was reversed on the second day. Overall, 69 subjects participated in the role of buyer and 71 subjects in the role of seller. ${ }^{7}$

All sessions took place at the decision laboratory of the Department of Economics at the University of Zurich. Subjects were students from the University of Zurich and the Swiss Federal Institute of Technology in Zurich and were recruited using the software "hroot" (Bock et al., 2014). Each subject participated only once, either as seller or buyer. Sessions lasted about 75 minutes. On average, subjects earned CHF 36.21, which includes a show-up fee of CHF 25. In addition, 19 of our subjects also took home a box of chocolates.

\section{Results}

We start by analyzing the decisions of buyers and sellers in Part I. Buyers and sellers indicated their maximum willingness-to-pay (WTP) and minimum willingness-to-accept (WTA) for a card

\footnotetext{
${ }^{5}$ Prior to conducting the experiment, we contracted a professional voice artist (hired through fiverr.com) to record audio files of the instructions. The audio files are provided in the Online Appendix, along with other materials from the instructions.

${ }^{6}$ The experiments were run with the software "z-Tree" (Fischbacher, 2007). Program files are available at the Online Appendix.

${ }^{7}$ The study was conducted in English. One subject in the role of seller had to be excused from the study due to a lack of fluency in English. The analysis thus comprises 139 subjects in total.
} 
worth $8.50 \mathrm{CHF}$, respectively. If subjects simply seek to maximize monetary earnings, then subjects' true WTP and WTA for this card should both be $8.50 \mathrm{CHF}$. Our price-list design does not allow us to observe valuations with high precision. What we can identify is that, for instance, a buyer who is willing to pay $X$ but not $X+1$ must have a valuation in the interval, WTP $\in[X, X+1)$. Similarly, a seller who is willing to accept $X+1$ but not $X$ must have a valuation in the interval, WTA $\in(X, X+1]$. Therefore, in our analysis we use the mid-point of the two values between which a buyer switches from buying to not buying or a seller switches from not selling to selling, $(X+X+1) / 2$, as our estimate of the WTA or WTP value for that subject. ${ }^{8}$

Overall, 98 of 139 subjects (70.5 percent) made choices consistent with WTA and WTP values of $8.50 \mathrm{CHF}$. More precisely, 53 out of 69 subjects (i.e. 76.8 percent) in the buyer condition switched between buying and not buying between 8 and 9 CHF and 45 out of 70 subjects (i.e. 63.4 percent) in the seller condition switched between not selling and selling in the same interval.

The mean estimates of WTP and WTA for the card are 8.43 CHF and 9.01 CHF, respectively. These values are also provided in the first column of Table 1 . The left panel of Figure 1 presents the cumulative frequencies of estimated WTP and WTA values. The two frequencies overlap considerably, indicating little difference between the estimated valuations for buyers and sellers for the card with known value of 8.50 CHF. Consistent with the differences in means, there are slightly more high value estimates for the sellers than for buyers. However, the difference between the means is only marginally significant (two sided t-test ${ }^{9}, \mathrm{p}=0.083$ ) and the two distributions do not differ significantly (K-S test, $\mathrm{p}=0.698)$.

In both conditions, we observe underpaying as well as overpaying. Of the 16 buyers with estimated WTP other than $8.50 \mathrm{CHF}$, exactly 8 underpaid and 8 overpaid for the card. In the seller condition, 9 subjects yielded WTA estimate values below 8.50 CHF and 16 gave values greater than $8.50 \mathrm{CHF}$. However, neither of these proportions differs significantly from $50 \%$ (two-sided binomial test, $\mathrm{p}=1$ and $\mathrm{p}=0.230$, respectively).

These findings demonstrate, firstly, that our BDM procedure for eliciting WTP and WTA resulted in fewer deviations from the optimum than the Cason and Plott design, where only 41 out of $245(16.7 \%)$ of their subjects chose the payoff maximizing WTA. Secondly, we find that

\footnotetext{
${ }^{8}$ If a subject chose a corner solution, i.e. chose to buy or sell at any or at no price in the list, we use the respective boundary of the price list as WTP or WTA. For example, if a subject chose not to sell the box of chocolate at any price, then we assign a WTA of 20 for that subject. In total, 2 subjects made such choices.

${ }^{9}$ All t-tests reported in this paper are corrected for unequal variances.
} 
deviations are relatively balanced and thus do not indicate that subjects treated the prices they provided as the prices they were to have to pay as buyers or that they would receive as sellers (e.g, as in a first price auction).

Result 1: Overall, 98 out of 139 subjects provided choices that maximized their monetary payoffs in the valuation task for the object with known value. For those subjects who did not do so, we find little evidence of systematic mistakes in one direction or of differences between buyers and sellers.

After subjects indicated their WTP or WTA in Part I, we asked them to calculate, for every possible random price realization, their final payoff given their choice. Overall, 54 out of 69 buyers (78.3 percent) and 58 out of 70 sellers ( 82.9 percent) correctly calculated their final payoff for every possible price on the first attempt. Hence, on aggregate, 80.6 percent of subjects showed a clear understanding of the payoff implications of their choices, providing another indication of relatively low miscomprehension of the incentive properties of the BDM. ${ }^{10}$

\begin{tabular}{cccccc}
\hline \hline & $\begin{array}{c}\text { Card } \\
\text { (all subjects) }\end{array}$ & $\begin{array}{c}\text { Chocolate } \\
\text { (all subjects) }\end{array}$ & $\begin{array}{c}\text { Chocolate } \\
\text { (sophisticated) }\end{array}$ & $\begin{array}{c}\text { Chocolate } \\
\text { (confused) }\end{array}$ & $\begin{array}{c}\text { p-value } \\
\text { (sophisticated } \\
\text { vs. confused) }\end{array}$ \\
\hline WTP & 8.43 & 4.78 & 4.63 & 5.00 & \\
$($ Buyer $)$ & $(0.191$, & $(0.377$, & $(0.468$, & $(0.635$, & 0.645 \\
& $\mathrm{~N}=69)$ & $\mathrm{N}=69)$ & $\mathrm{N}=41)$ & $\mathrm{N}=28)$ & \\
WTA & 9.01 & 8.62 & 7.65 & 9.91 & 0.071 \\
$($ Seller $)$ & $(0.276$, & $(0.612$, & $(0.765$, & $(0.962$, & \\
\hline p-value & $\mathrm{N}=70)$ & $\mathrm{N}=70)$ & $\mathrm{N}=40)$ & $\mathrm{N}=30)$ & \\
$\begin{array}{l}\text { (WTP vs. } \\
\text { WTA })\end{array}$ & 0.083 & 0.000 & 0.001 & 0.000 & \\
\hline \hline
\end{tabular}

Table 1: Mean estimated WTP and WTA in CHF. Numbers in brackets are standard errors and number of subjects. P-values are from two-sided t-tests.

\footnotetext{
${ }^{10}$ Out of those 53 buyers with estimated WTP of $8.50 \mathrm{CHF}, 43$ correctly calculated their final payoffs on the first try and so did 11 out of the 16 buyers who with estimated WTP different from 8 CHF. Out of those 45 sellers with estimated WTA of $8.50 \mathrm{CHF}, 40$ correctly calculated their final payoffs on the first try and so did 18 out of 25 with estimated WTA different from 8.50 CHF. Therefore, for both buyers and sellers, the proportion of those who correctly calculated their final payoff on the first try is higher for subjects who made the payoff maximizing choice (81.1 percent vs 68.8 percent and 88.9 percent vs. 72 percent, respectively).
} 
In Part II, subjects indicated their WTP and WTA for a box of chocolates. We again obtain WTP and WTA estimates for each subject by taking the midpoint of the prices at which that subject switched from buying to not buying or from not selling to selling. Taking all subjects into account, the WTA for the box of chocolates was significantly higher than the WTP (4.78 CHF vs. 8.62 CHF; two-sided t-test, $\mathrm{p}<0.01$ ). Hence, even with our design, with far less evidence of misconception in Part I than in Cason and Plott's study, and with almost no evidence of systematic bias in Part I stated valuations, we find a strong endowment effect.

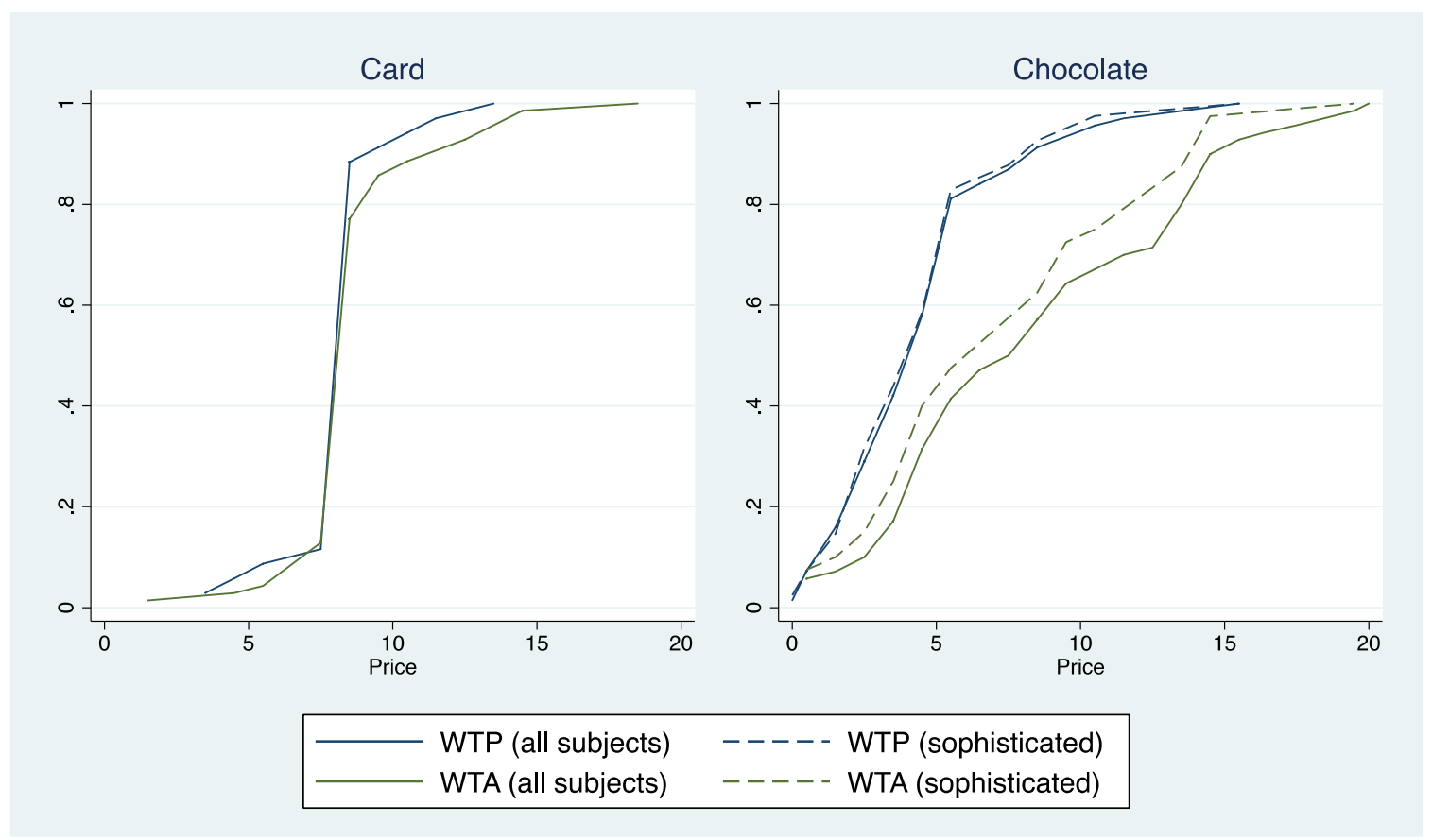

Figure 1: Cumulative distribution functions of WTP and WTA estimates in Parts I and II.

However, regarding this as evidence that the endowment effect is robust to subjects fully understanding the BDM mechanism is not entirely convincing, since our analysis of Part I indicates that a non-trivial proportion of subjects did exhibit behavior consistent with misconceptions about the BDM's incentive properties.

To see whether heterogeneity in subject misconceptions can account for Part II behavior that looks like the endowment effect, we divide our subject sample into two groups. We label as "sophisticated" those subjects who appear to completely understand the incentive properties of the BDM mechanism. This group consists of those subjects who chose the payoff maximizing 
switching point in Part I (between prices of $8 \mathrm{CHF}$ and $9 \mathrm{CHF}$ ) and who correctly calculated the final payoff for all possible prices on their first attempt, in both Part I as well as in Part II. Hence, this group, which consists of 41 buyers and 40 sellers, ${ }^{11}$ or 58.3 percent of our total sample, satisfies fairly strong requirements for being classified as understanding the incentive properties of the BDM mechanism. This group not only made the payoff-maximizing choice in the Part I valuation task-which is Cason and Plott's requirement for BDM game-form sophistication—but also had to correctly provide two sets of 21 payoff calculations, each on their first attempt.

The second group, which we label "confused," comprises subjects who failed at least one of the three conditions. Hence, this group either provided dominated choices in Part I, or made at least one mistake in one of the two sets of payoff calculations.

A closer look at the composition of the two groups reveals that those subjects who score higher on the Ravens Progressive Matrices test are significantly more likely to be "sophisticated," while there is no relationship between sophistication and the score on the Cognitive Reflection Test (CRT) (see Table A in the Appendix). Hence, by at least one measure, subjects in the "sophisticated" group are smarter on average, which lends further support to the notion that those subjects understood the BDM mechanism correctly.

As Table 1 reveals, there is no difference in WTP estimates and a marginally significant difference in WTA estimates for the box of chocolate between the two groups $(\mathrm{WTP}($ sophisticated $)=4.63 \mathrm{CHF}$ vs. WTP $($ confused $)=5.00 \mathrm{CHF}$, two-sided t-test, $\mathrm{p}=0.645$; $\mathrm{WTA}($ sophisticated $)=7.65 \mathrm{CHF}$ vs. WTP(confused $)=9.91 \mathrm{CHF}$, two-sided t-test, $\mathrm{p}=0.071)$. Furthermore, as Figure 1 shows, the distributions of estimated WTP and WTA values are similar for the two groups and do not differ significantly ( $\mathrm{K}-\mathrm{S}$ test, $\mathrm{p}=1.000$ and $\mathrm{p}=0.430$, respectively).

Finally, and most importantly, WTA estimates are significantly greater than WTP estimates, even when we only consider sophisticated subjects (4.63 CHF vs $7.64 \mathrm{CHF}$; two sided $\mathrm{t}$-test $\mathrm{p}=0.001$ ). This significant difference is also evident when comparing the distributions in Figure 1 (K-S test, $\mathrm{p}=0.010)$. Therefore, game form misconceptions do not explain the endowment effect.

\footnotetext{
${ }^{11}$ Only 1 out of 70 sellers and 3 out of 69 buyers incorrectly calculated their final payoffs in Part II.
} 
Result 2: Estimated WTA for a box of chocolates is significantly higher than estimated WTP for the same box of chocolates. This result holds even for subjects with high levels of understanding of the incentive properties of the BDM mechanism.

\section{Conclusion}

We follow up on the claim by Cason and Plott (forthcoming) that "the failure of game form recognition can masquerade as support for the theory of framing, as preferences constructed from reference points." They support this claim by showing that a BDM experiment in which there is a lot of misconception can produce data that looks like the behavior of sellers in an endowment effect experiment. While this claim might be true in some data sets, such as the one collected by Cason and Plott, they leave unanswered the important question whether framing effects persist for subjects who do not suffer from game form misconceptions.

In our paper, we employ a design that allows us to clearly identify whether subjects comprehend the incentive properties of a price-list version of the BDM mechanism. Our main result is that the endowment effect persists for subjects who revealed their understanding of the game form of the BDM mechanism. We can thus conclude that game form misconceptions do not explain the endowment effect.

\section{References}

Becker, Gordon M., Morris H. DeGroot, and Jacob Marschak.1964. "Measuring Utility by a Single-Response Sequential Method,” Behavioral Science, 9(3): 226-232.

Bock, Olaf, Ingmar Baetge, and Andreas Nicklisch. 2014. "hroot: Hamburg Registration and Organization Online Tool,” European Economic Review, 71: 117.

Cason, Timothy N. and Charles R. Plott. "Misconceptions and Game Form Recognition: Challenges to Theories of Revealed Preferences and Framing," Journal of Political Economy, forthcoming

Fischbacher, Urs. 2007. "z-Tree: Zurich Toolbox for Ready-made Economic Experiments," Experimental Economics, 10: 171-78.

Frederick, Shane. 2005. "Cognitive reflection and decision making," Journal of Economic Perspectives, 19(4): 25-42. 
Kahneman, Daniel, Jack L. Knetch, and Richard H. Thaler. 1990. "Experimental Tests of the Endowment Effect and the Coase Theorem," Journal of Political Economy, 98(6): 1325-48.

Kahneman, Daniel, Jack L. Knetch, and Richard H. Thaler. 1991. “Anomalies: The Endowment Effect, Loss Aversion, and Status Quo Bias," Journal of Economic Perspectives, 5(1): 193-206.

Marzilli Ericson, Keith M. and Andreas Fuster. 2014. "The Endowment Effect," Annual Review of Economics, 6: 555-79.

Murphy, James J., Thomas H. Stevens and Lava Yadav. 2010. “A Comparison of Induced Value and Home-Grown Value Experiments to Test for Hypothetical Bias in Contingent Valuation," Environmental and Resource Economics, 47(1): 111-123.

Plott, Charles R. and Kathryn Zeiler. 2005. "The Willingness to Pay-Willingness to Accept Gap, the "Endowment Effect," Subject Misconceptions, and Experimental Procedures for Eliciting Valuations," American Economic Review, 95(3): 530-45.

Plott, Charles R. and Kathryn Zeiler. 2007. "Exchange Asymmetries Incorrectly Interpreted as Evidence of Endowment Effect Theory and Prospect Theory?" American Economic Review, 97(4): 1449-66.

Raven, John C., John Raven, and John Court. 2007. Manual for Raven's Progressive Matrices and Vocabulary Scales. Harcourt Assessment, San Antonio, TX. 


\section{Appendix}

Table A.1: Probit regression

\begin{tabular}{|c|c|}
\hline $\begin{array}{l}\text { Dependent variable: } \\
\text { "Sophistication" }\end{array}$ & Probit regression \\
\hline Raven's task score & $\begin{array}{l}0.172 * * * \\
(0.059)\end{array}$ \\
\hline CRT score & $\begin{array}{l}-0.001 \\
(0.001)\end{array}$ \\
\hline Constant & $\begin{array}{l}-1.052 * * \\
(0.517) \\
\end{array}$ \\
\hline Observations & 139 \\
\hline Pseudo $\mathrm{R}^{2}$ & 0.064 \\
\hline \multicolumn{2}{|c|}{$\begin{array}{l}\text { Notes: The dependent variable is a binary variable taking on } \\
\text { value } 1 \text { if a subject is categorized as "sophisticated" and 0 } \\
\text { otherwise. Raven's task score denotes the number of correctly } \\
\text { solved puzzles (out of } 12 \text { ). CRT score measures the number of } \\
\text { correct answers in the cognitive reflection test (out of } 3 \text { ). } \\
\text { Robust standard errors are reported in parenthesis. } \\
* * * \text { denote significance at } 1 \text { percent, ** at } 5 \text { percent, and * at } \\
10 \text { percent. }\end{array}$} \\
\hline
\end{tabular}




\section{Online Appendix}

\section{A.1 Instructions for Buyers}

\section{Instructions for Participants}

Welcome to this study.

Please read through the following instructions, while they are read aloud. They explain everything you need to know for participating in the study. If you have any questions after listening to the instructions, please raise your hand and wait. We will then come to you and answer them.

During the study, speaking with the other participants and the use of mobile phones are forbidden. Violation of these rules will lead to exclusion from the study and loss of all associated payments.

\section{The Study}

You begin the study with an endowment of 25 CHF. During the study, the amount of money you have may vary, based on your decisions. Whatever final amount you end up with will be paid to you in cash at the end of the study.

In this study you will make two decisions; one in Part I, and one in Part II. You will first receive instructions for Part I and will make your decision for Part I. You will then receive instructions and make your decision for Part II. The decision you make in one part will have no effect on anything that happens in the other part.

At the end of the study, one of the two parts will be randomly drawn with equal probability to be the only part that counts for determining your payment. The part that is not selected to count will have no effect on your earnings. That is, either Part I or Part II, but not both, will determine your entire earnings for the study. 


\section{Part I}

In Part I you have the option to buy a card worth 8.5 CHF. The card is located in front of you at your computer terminal. If you buy the card, you can redeem it for $8.5 \mathrm{CHF}$ from the experimenter at the end of the study.

\section{Your task in Part I is to indicate the highest price you are willing to pay to buy the card.}

At the end of the study, the computer will randomly draw a price between 0 and $20 \mathrm{CHF}$, in increments of $1 \mathrm{CHF}$. This will be the price at which you can buy the card. You will not know the actual price until the end of the study.

You will decide, for each possible price, whether to buy or not buy the card at that price.

- If you buy the card, you can redeem it for $8.5 \mathrm{CHF}$, but you have to pay the price out of your initial $25 \mathrm{CHF}$.

- If you do not buy the card, you cannot redeem it for 8.5 CHF, but you do not have to pay any price out of your initial $25 \mathrm{CHF}$.

You will make your buying decision on a screen that looks like the table below. Please take a moment to look at this table.

\begin{tabular}{|c|c|c|c|c|}
\hline $\begin{array}{c}\text { Final Payoff } \\
\text { (25 CHF - price } \\
+ \text { value of card) }\end{array}$ & $\begin{array}{c}\text { I buy at this } \\
\text { price }\end{array}$ & $\begin{array}{c}\text { Price } \\
\text { (one row randomly } \\
\text { selected to count) }\end{array}$ & $\begin{array}{l}\text { I do not buy } \\
\text { at this price }\end{array}$ & $\begin{array}{l}\text { Final Payoff } \\
(25 \mathrm{CHF})\end{array}$ \\
\hline $33.5 \mathrm{CHF}$ & $\square$ & $0 \mathrm{CHF}$ & $\square$ & $25 \mathrm{CHF}$ \\
\hline $32.5 \mathrm{CHF}$ & $\square$ & $1 \mathrm{CHF}$ & $\square$ & $25 \mathrm{CHF}$ \\
\hline $31.5 \mathrm{CHF}$ & $\square$ & $2 \mathrm{CHF}$ & $\square$ & $25 \mathrm{CHF}$ \\
\hline$\ldots$ & $\ldots$ & $\ldots$ & $\ldots$ & $\ldots$ \\
\hline $26.5 \mathrm{CHF}$ & $\square$ & 7 CHF & $\square$ & $25 \mathrm{CHF}$ \\
\hline $25.5 \mathrm{CHF}$ & $\square$ & 8 CHF & $\square$ & $25 \mathrm{CHF}$ \\
\hline $24.5 \mathrm{CHF}$ & $\square$ & 9 CHF & $\square$ & $25 \mathrm{CHF}$ \\
\hline$\ldots$ & $\ldots$ & ... & $\ldots$ & $\ldots$ \\
\hline $15.5 \mathrm{CHF}$ & $\square$ & $18 \mathrm{CHF}$ & $\square$ & $25 \mathrm{CHF}$ \\
\hline $14.5 \mathrm{CHF}$ & $\square$ & $19 \mathrm{CHF}$ & $\square$ & $25 \mathrm{CHF}$ \\
\hline $13.5 \mathrm{CHF}$ & $\square$ & $20 \mathrm{CHF}$ & $\square$ & $25 \mathrm{CHF}$ \\
\hline
\end{tabular}


Each row in the table corresponds to one of the possible prices. The prices are indicated in the middle column of the table, in bold. Remember that the computer will randomly select one price to count. Your choice in this row, if Part I is selected to count, will determine your payoff from the study.

You will choose, for each possible row, whether to buy or not buy the card at the price given in that row. You will indicate your choice in each row, by clicking the box on the left if you choose to buy at that price and the box on the right if you choose not to buy at that price.

The final payoff that you receive from buying at a given price is shown in the left column and the final payoff from not buying at a given price is shown in the right column.

\section{Examples:}

- Suppose you indicate that you want to buy the card at a price of 2 CHF (by checking the left box in that line) and the price of 2 CHF is randomly drawn, then your payoff would be $31.5 \mathrm{CHF}$ (25 CHF - $2 \mathrm{CHF}+8.5 \mathrm{CHF}$ ). If, instead, you indicate not to buy the card at a price of $2 \mathrm{CHF}$, your payoff would be $25 \mathrm{CHF}$.

- Suppose you indicate that you want to buy the card at a price of $18 \mathrm{CHF}$ and the price of $18 \mathrm{CHF}$ is randomly drawn, then your payoff would be $15.5 \mathrm{CHF}$ (25 CHF - $18 \mathrm{CHF}+$ $8.5 \mathrm{CHF}$ ). If, instead, you indicate not to buy the card at a price of $18 \mathrm{CHF}$, your payoff would be 25 CHF.

Remember that we are asking you for the highest price at which you are willing to buy the card. This means that you should select "buy" for all of the rows that correspond to prices below the highest price you are willing to pay, and should select "do not buy" for all the rows that correspond to prices above the highest price you are willing to pay. The computer will not allow you to make inconsistent choices in which you indicate not to buy the card at some price, but then indicate to buy it at a higher price. That is, there should be only one price at which you switch from buying the card to not buying the card.

Remember that there is a 50 percent chance that Part I will be selected to determine all your earnings for the study. Therefore, please think carefully about your decision.

Are there any questions about Part I, before we proceed to the decision screen? If you have a question, please raise your hand and wait for an experimenter. 


\section{Part II}

In Part II you have the option to buy a box of chocolate. The box is located in front of you at your computer terminal. If you buy the box, you can take it home with you at the end of the study.

Your task in Part II is to indicate the highest price you are willing to pay to buy the box of chocolate.

At the end of the study, the computer will randomly draw a price between 0 and $20 \mathrm{CHF}$, in increments of $1 \mathrm{CHF}$. This will be the price at which you can buy the box of chocolates. You will not know the actual price until the end of the study.

You will decide, for each possible price, whether to buy or not buy the box of chocolate at that price.

- If you buy the box of chocolate, you can take it home, but you have to pay the price out of your initial $25 \mathrm{CHF}$.

- If you do not buy the box of chocolate, you cannot take it home, but you do not have to pay any price out of your initial $25 \mathrm{CHF}$.

You will make your buying decision on a screen that looks like the table below. Please take a moment to look at this table.

\begin{tabular}{|c|c|c|c|c|}
\hline $\begin{array}{c}\text { Final Payoff } \\
\text { (25 CHF - price + } \\
\text { box of chocolate) }\end{array}$ & $\begin{array}{c}\text { I buy at } \\
\text { this price }\end{array}$ & $\begin{array}{c}\text { Price } \\
\text { (one row randomly } \\
\text { selected to count) }\end{array}$ & $\begin{array}{c}\text { I do not buy } \\
\text { at this price }\end{array}$ & $\begin{array}{c}\text { Final Payoff } \\
\text { (25 CHF) }\end{array}$ \\
\hline $25 \mathrm{CHF}+$ chocolate & $\square$ & $\mathbf{0 ~ C H F ~}$ & $\square$ & $25 \mathrm{CHF}$ \\
\hline $24 \mathrm{CHF}+$ chocolate & $\square$ & $\mathbf{1 ~ C H F}$ & $\square$ & $25 \mathrm{CHF}$ \\
\hline $23 \mathrm{CHF}+$ chocolate & $\square$ & $\mathbf{2 ~ C H F}$ & $\square$ & $25 \mathrm{CHF}$ \\
\hline$\ldots$ & $\ldots$ & $\ldots$ & $\ldots$ & $\ldots$ \\
\hline $18 \mathrm{CHF}+$ chocolate & $\square$ & $\mathbf{7 ~ C H F}$ & $\square$ & $25 \mathrm{CHF}$ \\
\hline $17 \mathrm{CHF}+$ chocolate & $\square$ & $\mathbf{8 ~ C H F}$ & $\square$ & $25 \mathrm{CHF}$ \\
\hline $16 \mathrm{CHF}+$ chocolate & $\square$ & $\mathbf{9 ~ C H F}$ & $\square$ & $25 \mathrm{CHF}$ \\
\hline$\ldots$ & $\ldots$ & $\mathbf{. .}$ & $\ldots$ & $\ldots$ \\
\hline $7 \mathrm{CHF}+$ chocolate & $\square$ & $\mathbf{1 8 ~ C H F}$ & $\square$ & $25 \mathrm{CHF}$ \\
\hline $6 \mathrm{CHF}+$ chocolate & $\square$ & $\mathbf{1 9} \mathbf{C H F}$ & $\square$ & $25 \mathrm{CHF}$ \\
\hline $5 \mathrm{CHF}+$ chocolate & $\square$ & $\mathbf{2 0 ~ C H F}$ & $\square$ & $25 \mathrm{CHF}$ \\
\hline
\end{tabular}


Each row in the table corresponds to one of the possible prices. The prices are indicated in the middle column of the table, in bold. Remember that the computer will randomly select one price to count. Your choice in this row, if Part II is selected to count, will determine your payoff from the study.

You will choose, for each possible row, whether to buy or not buy the box of chocolate at the price given in that row. You will indicate your choice in each row, by clicking the box on the left if you choose to buy at that price and the box on the right if you choose not to buy at that price.

The final payoff that you receive from buying at a given price is shown in the left column and the final payoff from not buying at a given price is shown in the right column.

\section{Examples:}

- Suppose you indicate that you want to buy the box of chocolate at a price of 2 CHF (by checking the left box in that line) and the price of 2 CHF is randomly drawn, then your payoff would be $23 \mathrm{CHF}$ (25 CHF - $2 \mathrm{CHF}$ ) plus the box of chocolate. If, instead, you indicate not to buy the box of chocolate at a price of $2 \mathrm{CHF}$, your payoff would be 25 CHF.

- Suppose you indicate that you want to buy the box of chocolate at a price of $18 \mathrm{CHF}$ and the price of $18 \mathrm{CHF}$ is randomly drawn, then your payoff would be 7 CHF (25 CHF - 18 $\mathrm{CHF}$ ) plus the box of chocolate. If, instead, you indicate not to buy the box of chocolate at a price of $18 \mathrm{CHF}$, your payoff would be $25 \mathrm{CHF}$.

Remember that we are asking you for the highest price at which you are willing to buy the box of chocolate. This means that you should select "buy" for all of the rows that correspond to prices below the highest price you are willing to pay, and should select "do not buy" for all the rows that correspond to prices above the highest price you are willing to pay. The computer will not allow you to make inconsistent choices in which you indicate not to buy the box of chocolate at some price, but then indicate to buy it at a higher price. That is, there should only be one price at which you switch from buying the box of chocolate to not buying the box of chocolate.

Remember that there is a 50 percent chance that Part II will be selected to determine all your earnings for the study. Therefore, please think carefully about your decision.

Are there any questions about Part II, before we proceed to the decision screen? If you have a question, please raise your hand and wait for an experimenter. 


\section{A.2 Decision screens for Buyers}

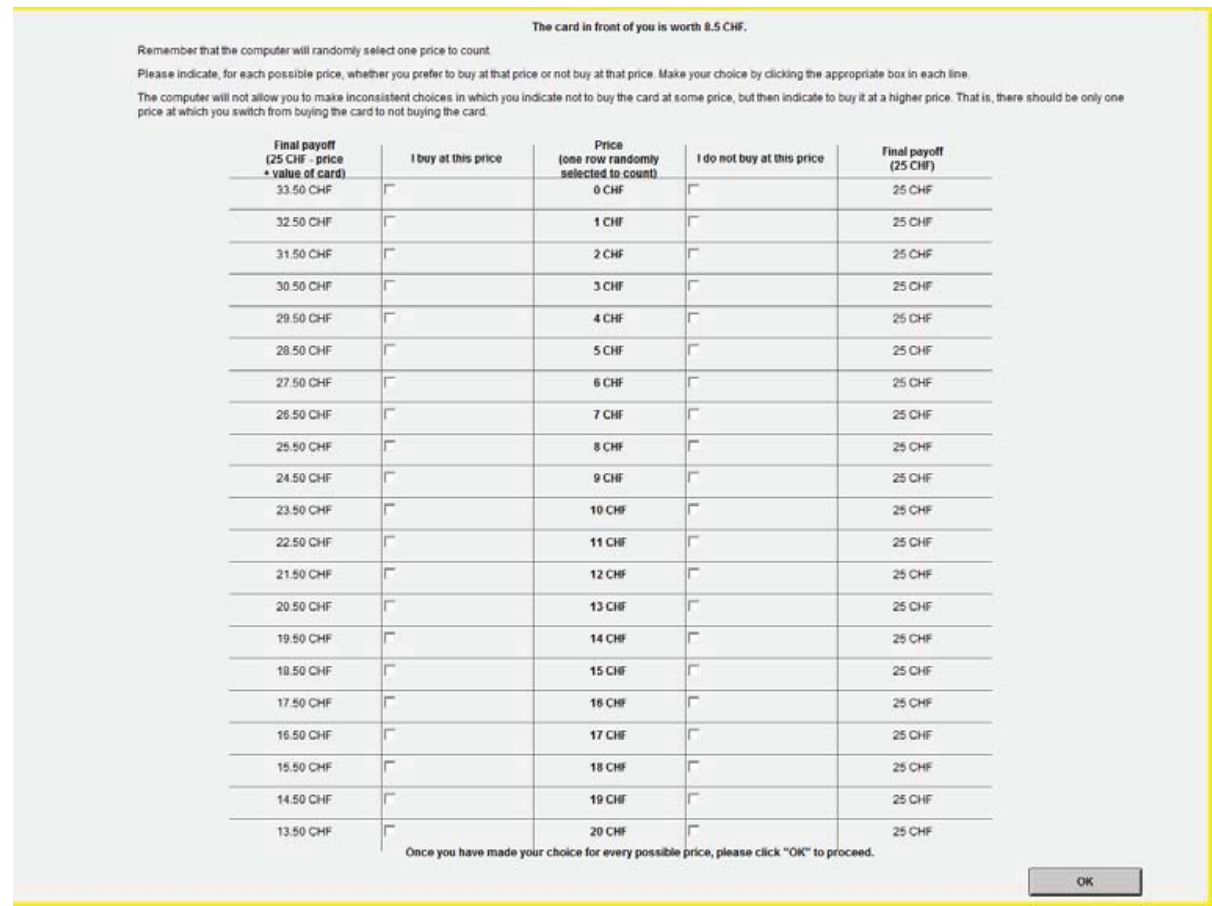

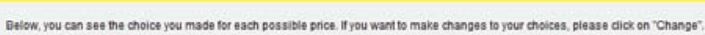

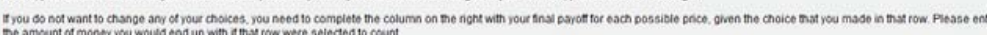

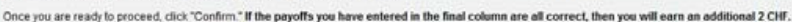

\begin{tabular}{|c|c|c|c|c|c|}
\hline 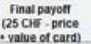 & Boy at this price & $\begin{array}{l}\text { Price } \\
\text { cone row randomy } \\
\text { selected t to counn }\end{array}$ & Dos sot tov at atis price & $\begin{array}{l}\text { Tinal payolf } \\
\text { (25 Clif) }\end{array}$ & $\begin{array}{l}\text { Your fnal peyout } \\
\text { (in CHIf) }\end{array}$ \\
\hline & F & OCHS & I & $25 \mathrm{CHF}$ & \\
\hline $3250 \mathrm{CHF}$ & F & toir & r & 25 CHF & \\
\hline $31.50 \mathrm{CHF}$ & $F$ & $2 \mathrm{CHF}$ & $r$ & $25 \mathrm{CHF}$ & \\
\hline 30.50 CHF & F & $30 \mathrm{GS}$ & $r$ & 25 CHF & \\
\hline $29.50 \mathrm{CHF}$ & F & 4 Cir & $r$ & 25 CHF & \\
\hline $28.50 \mathrm{CHF}$ & 7 & 5 CHF & $r$ & $25 \mathrm{CHF}$ & \\
\hline 27.50 CHF & F & $6 \mathrm{CH}$ & r & 25 CHF & \\
\hline $26.50 \mathrm{CHF}$ & F & 70 if & r & $25 \mathrm{CH}$ & \\
\hline 25,50 CHF & F & BCHF & r & $25 \mathrm{CHF}$ & \\
\hline 2450 CHF & $r$ & $9 \mathrm{Cas}$ & F & 25 CHF & \\
\hline 2350 CHr & $r$ & $10 \mathrm{CHF}$ & F & 25 CHF & \\
\hline 2250 CHF & r & " CHF & F & $25 \mathrm{CHF}$ & \\
\hline 21.50 CMF & r & $12 \mathrm{CHF}$ & F & 25 CHF & \\
\hline 20.50 CHF & r & $13 \mathrm{CHF}$ & F & $250 \mathrm{ch}$ & \\
\hline 19.50 CHF & $\Gamma$ & 14 CHF & F & $25 \mathrm{CHF}$ & \\
\hline 10.50 Chf & $r$ & $15 \mathrm{CHF}$ & p & 25 CHF & \\
\hline 1750 CHF & r & $16 \mathrm{CHF}$ & F & 25 CHF & \\
\hline 16.50 C्Af & $\Gamma$ & $17 \mathrm{CHF}$ & P & 25 CHF & \\
\hline 15.50 ChF & r & $18 \mathrm{CHF}$ & p & 25 CHF & \\
\hline 1450 CHF & $r$ & $19 \mathrm{CHI}$ & F & 25 Chr & \\
\hline 1350 CHF & $\Gamma$ & $20 \mathrm{CHF}$ & F & $25 \mathrm{CHF}$ & \\
\hline
\end{tabular}



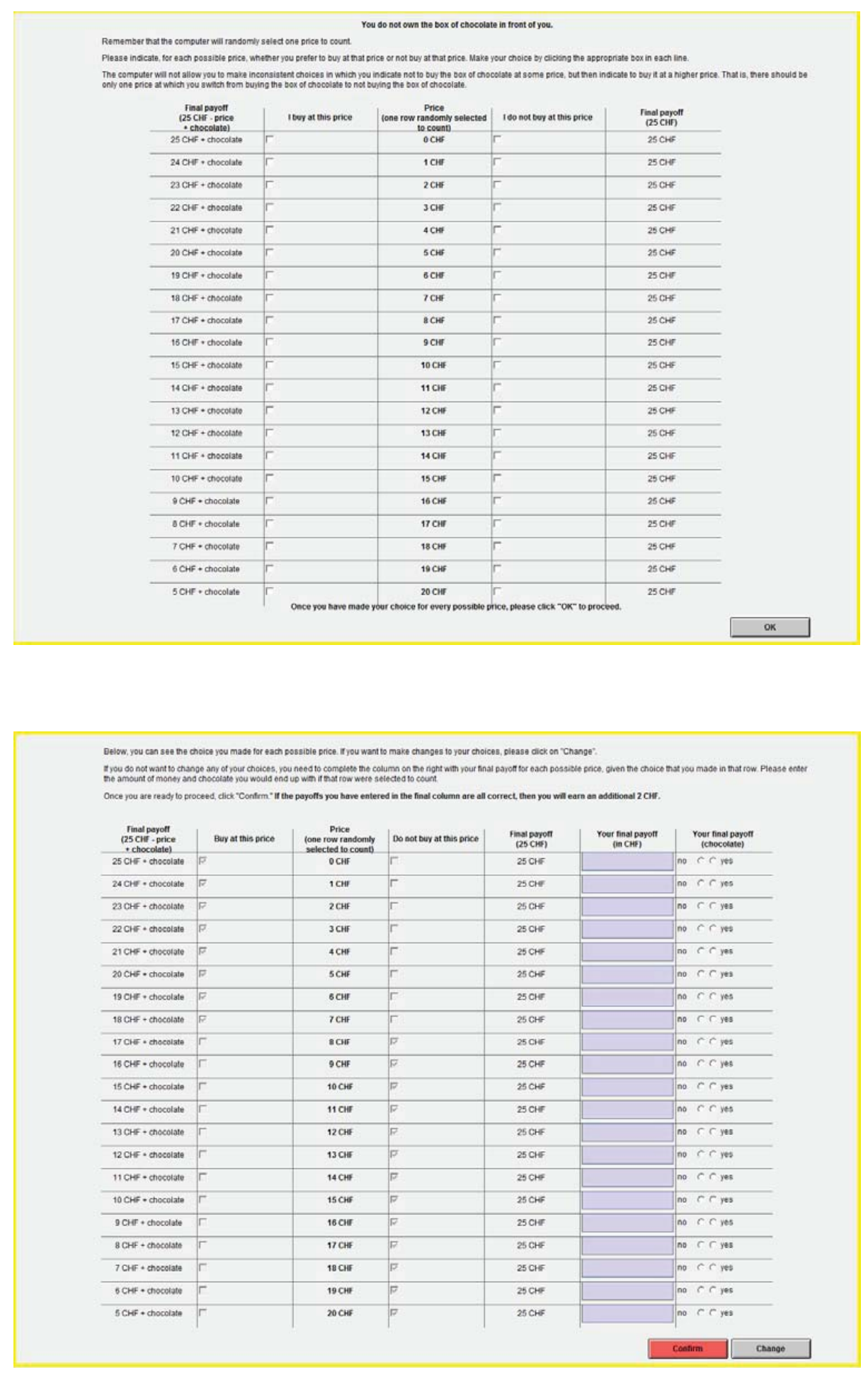


\section{B.1 Instructions for Sellers}

\section{Instructions for Participants}

Welcome to this study.

Please read through the following instructions, while they are read aloud. They explain everything you need to know for participating in the study. If you have any questions after listening to the instructions, please raise your hand and wait. We will then come to you and answer them.

During the study, speaking with the other participants and the use of mobile phones are forbidden. Violation of these rules will lead to exclusion from the study and loss of all associated payments.

\section{The Study}

You begin the study with an endowment of 25 CHF. During the study, the amount of money you have may vary, based on your decisions. Whatever final amount you end up with will be paid to you in cash at the end of the study.

In this study you will make two decisions; one in Part I, and one in Part II. You will first receive instructions for Part I and will make your decision for Part I. You will then receive instructions and make your decision for Part II. The decision you make in one part will have no effect on anything that happens in the other part.

At the end of the study, one of the two parts will randomly be drawn with equal probability to be the only part that counts for determining your payment. The part that is not selected to count will have no effect on your earnings. That is, either Part I or Part II, but not both, will determine your entire earnings for the study. 


\section{Part I}

In Part I you have the option to sell a card worth 8.5 CHF. The card is located in front of you at your computer terminal. The card is yours, you own it. If you do not sell the card, you can redeem it for $8.5 \mathrm{CHF}$ from the experimenter at the end of the study.

\section{Your task in Part I is to indicate the lowest price you are willing to accept to sell the card.}

At the end of the study, the computer will randomly draw a price between 0 and $20 \mathrm{CHF}$, in increments of $1 \mathrm{CHF}$. This will be the price at which you can sell the card. You will not know the actual price until the end of the study.

You will decide, for each possible price, whether to sell or not sell the card at that price.

- If you sell the card, you cannot redeem it for 8.5 CHF, but you receive the price, in addition to your initial $25 \mathrm{CHF}$.

- If you do not sell the card, you can redeem it for 8.5 CHF, in addition to your initial 25 $\mathrm{CHF}$, but you do not receive the price.

You will make your buying decision on a screen that looks like the table below. Please take a moment to look at this table.

\begin{tabular}{|c|c|c|c|c|}
\hline $\begin{array}{c}\text { Final Payoff } \\
\text { (CHF 25 + price) }\end{array}$ & $\begin{array}{c}\text { I sell at } \\
\text { this price }\end{array}$ & $\begin{array}{c}\text { Price } \\
\text { (one row randomly } \\
\text { selected to count) }\end{array}$ & $\begin{array}{c}\text { I do not sell } \\
\text { at this price }\end{array}$ & $\begin{array}{c}\text { Final Payoff } \\
\text { (CHF 25 }+ \\
\text { value of card) }\end{array}$ \\
\hline $25 \mathrm{CHF}$ & $\square$ & $\mathbf{0 ~ C H F ~}$ & $\square$ & $33.5 \mathrm{CHF}$ \\
\hline $26 \mathrm{CHF}$ & $\square$ & $\mathbf{1 ~ C H F}$ & $\square$ & $33.5 \mathrm{CHF}$ \\
\hline $27 \mathrm{CHF}$ & $\square$ & $\mathbf{2 ~ C H F}$ & $\square$ & $33.5 \mathrm{CHF}$ \\
\hline$\ldots$ & $\ldots$ & $\ldots$ & $\ldots$ & $\ldots$ \\
\hline $32 \mathrm{CHF}$ & $\square$ & $\mathbf{7 ~ C H F}$ & $\square$ & $33.5 \mathrm{CHF}$ \\
\hline $33 \mathrm{CHF}$ & $\square$ & $\mathbf{8 ~ C H F}$ & $\square$ & $33.5 \mathrm{CHF}$ \\
\hline $34 \mathrm{CHF}$ & $\square$ & $\mathbf{9 ~ C H F}$ & $\square$ & $33.5 \mathrm{CHF}$ \\
\hline$\ldots$ & $\ldots$ & $\mathbf{. .}$ & $\ldots$ & $\ldots$ \\
\hline $43 \mathrm{CHF}$ & $\square$ & $\mathbf{1 8 ~ C H F}$ & $\square$ & $33.5 \mathrm{CHF}$ \\
\hline $44 \mathrm{CHF}$ & $\square$ & $\mathbf{1 9} \mathbf{C H F}$ & $\square$ & $33.5 \mathrm{CHF}$ \\
\hline $45 \mathrm{CHF}$ & $\square$ & $\mathbf{2 0 ~ C H F}$ & $\square$ & $33.5 \mathrm{CHF}$ \\
\hline
\end{tabular}


Each row in the table corresponds to one of the possible prices. The prices are indicated in the middle column of the table, in bold. Remember that the computer will randomly select one price to count. Your choice in this row, if Part I is selected to count, will determine your payoff from the study.

You will choose, for each possible row, whether to sell or not sell the card at the price given in that row. You will indicate your choice in each row, by clicking the box on the left if you choose to sell at that price and the box on the right if you choose not to sell at that price.

The final payoff that you receive from selling at a given price is shown in the left column and the final payoff from not selling at a given price is shown in the right column.

\section{Examples:}

- Suppose you indicate that you want to sell the card at a price of 2 CHF (by checking the left box in that line) and the price of 2 CHF is randomly drawn, then your payoff would be $27 \mathrm{CHF}$ (25 CHF + $2 \mathrm{CHF}$ ). If, instead, you indicate not to sell the card at a price of 2 $\mathrm{CHF}$, your payoff would be $33.5 \mathrm{CHF}$ (25 CHF + 8.5 CHF).

- Suppose you indicate that you want to sell the card at a price of $18 \mathrm{CHF}$ and the price of $18 \mathrm{CHF}$ is randomly drawn, then your payoff would be $43 \mathrm{CHF}(25 \mathrm{CHF}+18 \mathrm{CHF})$. If, instead, you indicate not to sell the card at a price of $18 \mathrm{CHF}$, your payoff would be 33.5 CHF (25 CHF + 8.5 CHF).

Remember that we are asking you for the lowest price at which you are willing to sell the card. This means that you should select "sell" for all of the rows that correspond to prices above the lowest price you are willing to accept, and should select "do not sell" for all the rows that correspond to prices below the lowest price you are willing to accept. The computer will not allow you to make inconsistent choices in which you indicate to sell the card at some price, but then indicate not to sell it at a higher price. That is, there should only be one price at which you switch from not selling the card to selling the card.

Remember that there is a 50 percent chance that Part I will be selected to determine all your earnings for the study. Therefore, please think carefully about your decision.

Are there any questions about Part I, before we proceed to the decision screen? If you have a question, please raise your hand and wait for an experimenter. 


\section{Part II}

In Part II you have the option to sell a box of chocolate. The box is located in front of you at your computer terminal. The box is yours, you own it. If you do not sell the box, you can take it home with you at the end of the study.

Your task in Part II is to indicate the lowest price you are willing to accept to sell the box of chocolate.

At the end of the study, the computer will randomly draw a price between 0 and $20 \mathrm{CHF}$, in increments of $1 \mathrm{CHF}$. This will be price at which you can sell the box of chocolate. You will not know the actual price until the end of the study.

You will decide, for each possible price, whether to sell or not sell the box of chocolate at that price.

- If you sell the box of chocolate, you cannot take it home, but you receive the price in addition to your initial $25 \mathrm{CHF}$.

- If you do not sell the box of chocolate, you can take it home, in addition to your initial 25 $\mathrm{CHF}$, but you do not receive the price.

You will make your selling decision on a screen that looks like the table below. Please take a moment to look at this table.

\begin{tabular}{|c|c|c|c|c|}
\hline $\begin{array}{c}\text { Final Payoff } \\
\text { (CHF 25 + price) }\end{array}$ & $\begin{array}{c}\text { I sell at } \\
\text { this price }\end{array}$ & $\begin{array}{c}\text { Price } \\
\text { (one row randomly } \\
\text { selected to count) }\end{array}$ & $\begin{array}{c}\text { I do not sell } \\
\text { at this price }\end{array}$ & $\begin{array}{c}\text { Final Payoff } \\
\text { (CHF 25 + chocolate) }\end{array}$ \\
\hline $25 \mathrm{CHF}$ & $\square$ & $\mathbf{0 ~ C H F}$ & $\square$ & $25 \mathrm{CHF}+$ chocolate \\
\hline $26 \mathrm{CHF}$ & $\square$ & $\mathbf{1 ~ C H F}$ & $\square$ & $25 \mathrm{CHF}+$ chocolate \\
\hline $27 \mathrm{CHF}$ & $\square$ & $\mathbf{2 ~ C H F}$ & $\square$ & $25 \mathrm{CHF}+$ chocolate \\
\hline & $\square$ & & $\square$ & \\
\hline $32 \mathrm{CHF}$ & $\square$ & $\mathbf{7 ~ C H F}$ & $\square$ & $25 \mathrm{CHF}+$ chocolate \\
\hline $33 \mathrm{CHF}$ & $\square$ & $\mathbf{8 ~ C H F}$ & $\square$ & $25 \mathrm{CHF}+$ chocolate \\
\hline $34 \mathrm{CHF}$ & $\square$ & $\mathbf{9 ~ C H F}$ & $\square$ & $25 \mathrm{CHF}+$ chocolate \\
\hline & $\square$ & & $\square$ & \\
\hline $43 \mathrm{CHF}$ & $\square$ & $\mathbf{1 8} \mathbf{C H F}$ & $\square$ & $25 \mathrm{CHF}+$ chocolate \\
\hline $44 \mathrm{CHF}$ & $\square$ & $\mathbf{1 9} \mathbf{C H F}$ & $\square$ & $25 \mathrm{CHF}+$ chocolate \\
\hline $45 \mathrm{CHF}$ & $\square$ & $\mathbf{2 0 ~ C H F}$ & $\square$ & $25 \mathrm{CHF}+$ chocolate \\
\hline
\end{tabular}


Each row in the table corresponds to one of the possible prices. The prices are indicated in the middle column of the table, in bold. Remember that the computer will randomly select one price to count. Your choice in this row, if Part II is selected to count, will determine your payoff from the study.

You will choose, for each possible row, whether to sell or not sell the box of chocolate at the price given in that row. You will indicate your choice in each row, by clicking the box on the left if you choose to sell at that price and the box on the right if you choose not to sell at that price.

The final payoff that you receive from selling at a given price is shown in the left column and the final payoff from not selling at a given price is shown in the right column.

\section{Examples:}

- Suppose you indicate that you want to sell the box of chocolate at a price of 2 CHF (by checking the left box in that line) and the price of 2 CHF is randomly drawn, then your payoff would be $27 \mathrm{CHF}$ (25 CHF + 2 CHF). If, instead, you indicate not to sell the box of chocolate at a price of $2 \mathrm{CHF}$, your payoff would be CHF 25 plus the box of chocolate.

- Suppose you indicate that you want to sell the box of chocolate at a price of $18 \mathrm{CHF}$ and the price of $18 \mathrm{CHF}$ is randomly drawn, then your payoff would be $43 \mathrm{CHF}$ (25 CHF + $18 \mathrm{CHF}$ ). If, instead, you indicate not to sell the box of chocolate at a price of $18 \mathrm{CHF}$, your payoff would be CHF 25 plus the box of chocolate.

Remember that we are asking you for the lowest price at which you are willing to sell the box of chocolate. This means that you should select "sell" for all of the rows that correspond to prices above the lowest price you are willing to accept, and should select "do not sell" for all the rows that correspond to prices below the lowest price you are willing to accept. The computer will not allow you to make inconsistent choices in which you indicate to sell the box of chocolate at some price, but then indicate not to sell it at a higher price. That is, there should only be one price at which you switch from not selling the box of chocolate to selling the box of chocolate.

Remember that there is a 50 percent chance that Part II will be selected to determine all your earnings for the study. Therefore, please think carefully about your decision.

Are there any questions about Part II, before we proceed to the decision screen? If you have a question, please raise your hand and wait for an experimenter. 
B2. Decision screens for Sellers

\begin{tabular}{|c|c|c|c|c|c|}
\hline \multicolumn{6}{|c|}{ The card yoe com is worth $8.5 \mathrm{CHF}$. } \\
\hline \multirow{3}{*}{\multicolumn{6}{|c|}{ 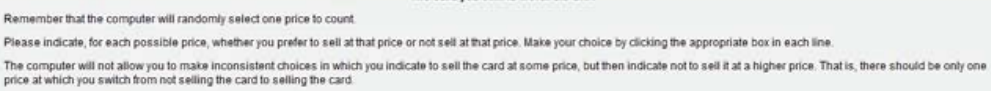 }} \\
\hline & & & & & \\
\hline & & & & & \\
\hline $\begin{array}{c}\text { Final payolt } \\
\text { (25CHF }+ \text { Drice) }\end{array}$ & I sell at this pitice & 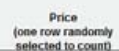 & Ido not sell at this price & $\begin{array}{l}\text { rinat payot } \\
\text { (25 CMF } * \text { value of care) }\end{array}$ & \\
\hline $25 \mathrm{CHF}$ & $r$ & 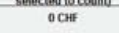 & $r$ & $33.5 \mathrm{CHF}$ & \\
\hline 26 CHF & $r$ & 1 CHF & $r$ & 335 ChF & \\
\hline 27 CHF & $r$ & 2 CHF & $r$ & 33.5 Cif & \\
\hline $2 \mathrm{CHF}$ & $r$ & JoHf & $r$ & 335 CHF & \\
\hline 29 CHF & $r$ & $4 \mathrm{CHI}$ & $r$ & 335 CHF & \\
\hline 30 CHF & $r$ & 5 CHF & $r$ & $335 \mathrm{CHF}$ & \\
\hline HOHF & $r$ & 6 Ciff & $r$ & 335 Chf & \\
\hline 32 CHF & $r$ & TCHF & $r$ & $33.5 \mathrm{CHF}$ & \\
\hline 33 CHF & $r$ & $8 \mathrm{CHF}$ & $r$ & $335 \mathrm{CHF}$ & \\
\hline 3 CHF & $r$ & शCHF & r & 235 ouf & \\
\hline 35 CHF & $r$ & $10 \mathrm{CHF}$ & $r$ & 33.5 CHF & \\
\hline 36 OHF & $r$ & $11 \mathrm{CHF}$ & r & 335 CHF & \\
\hline 3T CHF & $r$ & $12 \mathrm{CHF}$ & $r$ & 335 CHF & \\
\hline $38 \mathrm{CHF}$ & $r$ & 13CHF & r & $325 \mathrm{CHF}$ & \\
\hline rochf & $r$ & $14 \mathrm{CHF}$ & $r$ & 2350 chf & \\
\hline 40 CHF & $r$ & $15 \mathrm{CHF}$ & r & 33.5 CMF & \\
\hline 41 CHF & $r$ & $16 \mathrm{CHF}$ & $r$ & 335 CHF & \\
\hline $42 \mathrm{CHF}$ & $r$ & $17 \mathrm{cur}$ & $r$ & $335 \mathrm{CHF}$ & \\
\hline 43 CHF & $r$ & $18 \mathrm{CHF}$ & $r$ & $335 \mathrm{CHF}$ & \\
\hline 4OHF & $r$ & $19 \mathrm{CHF}$ & $r$ & 335 CHF & \\
\hline 45 CHF & r & & $r$ & $33.5 \mathrm{CHF}$ & \\
\hline & Once you have mar & choice tor every possi & Drice, pesse click -OK" to & raceed. & \\
\hline & & & & & ok \\
\hline
\end{tabular}

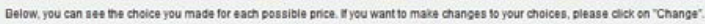

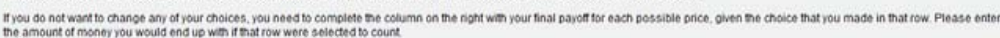

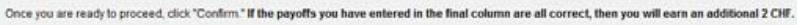

\begin{tabular}{|c|c|c|c|c|c|}
\hline 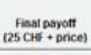 & Sell at this price & 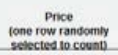 & Do not sell at this price & 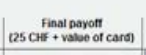 & $\begin{array}{l}\text { Your finat payout } \\
\text { (in CHF) }\end{array}$ \\
\hline $25 \mathrm{CHF}$ & I & & Fr & $335 \mathrm{CHF}$ & \\
\hline $26 \mathrm{CHF}$ & r & $1 \mathrm{CHF}$ & $F$ & $33.5 \mathrm{CHF}$ & \\
\hline $27 \mathrm{CHF}$ & Ir & $2 \mathrm{CHF}$ & F & 335 CHF & \\
\hline $28 \mathrm{CHF}$ & I & $3 \mathrm{CHF}$ & F & 33.5 cHF & \\
\hline $29 \mathrm{CHF}$ & r & 4 CHF & F & $33.5 \mathrm{CHF}$ & \\
\hline $30 \mathrm{Cor}$ & I & SCHF & F & $335 \mathrm{Carf}$ & \\
\hline 31 chf & $r$ & $6 \mathrm{CHF}$ & p & 335 chif & \\
\hline $32 \mathrm{CHF}$ & $r$ & TCHF & $F$ & 33.5 CHF & \\
\hline 33 CAf & Ir & $8 \mathrm{CHF}$ & if & 335 CMF & \\
\hline $34 \mathrm{CHF}$ & $F$ & $9 \mathrm{CHF}$ & r & $33.5 \mathrm{CHF}$ & \\
\hline 35 CHF & $\nabla$ & $10 \mathrm{CHF}$ & r & 335 CMF & \\
\hline $36 \mathrm{cHF}$ & $F$ & $11 \mathrm{CH}$ & r & $33.5 \mathrm{chr}$ & \\
\hline $37 \mathrm{CHF}$ & F & $12 \mathrm{CHF}$ & T & 335 CHF & \\
\hline $38 \mathrm{CHF}$ & p & 13 Cl: & r & $235 \mathrm{CHF}$ & \\
\hline $39 \mathrm{CHF}$ & F & $14 \mathrm{CHF}$ & $r$ & $33.5 \mathrm{CHF}$ & \\
\hline 40 CHF & $\nabla$ & 15 CHF & r & $335 \mathrm{CHF}$ & \\
\hline $41 \mathrm{CHF}$ & F & $16 \mathrm{cHF}$ & $r$ & $33.5 \mathrm{CHF}$ & \\
\hline $42 \mathrm{CHF}$ & F & $17 \mathrm{CHF}$ & r & 335 CMF & \\
\hline $43 \mathrm{CHF}$ & F & $18 \mathrm{CH}$ & r & 33.5 CHF & \\
\hline $4 \mathrm{CHF}$ & F & $19 \mathrm{CHF}$ & Tr & 33.5 CHF & \\
\hline 45 Crf & $F$ & $20 \mathrm{CHF}$ & r & $33.5 \mathrm{CHF}$ & \\
\hline
\end{tabular}




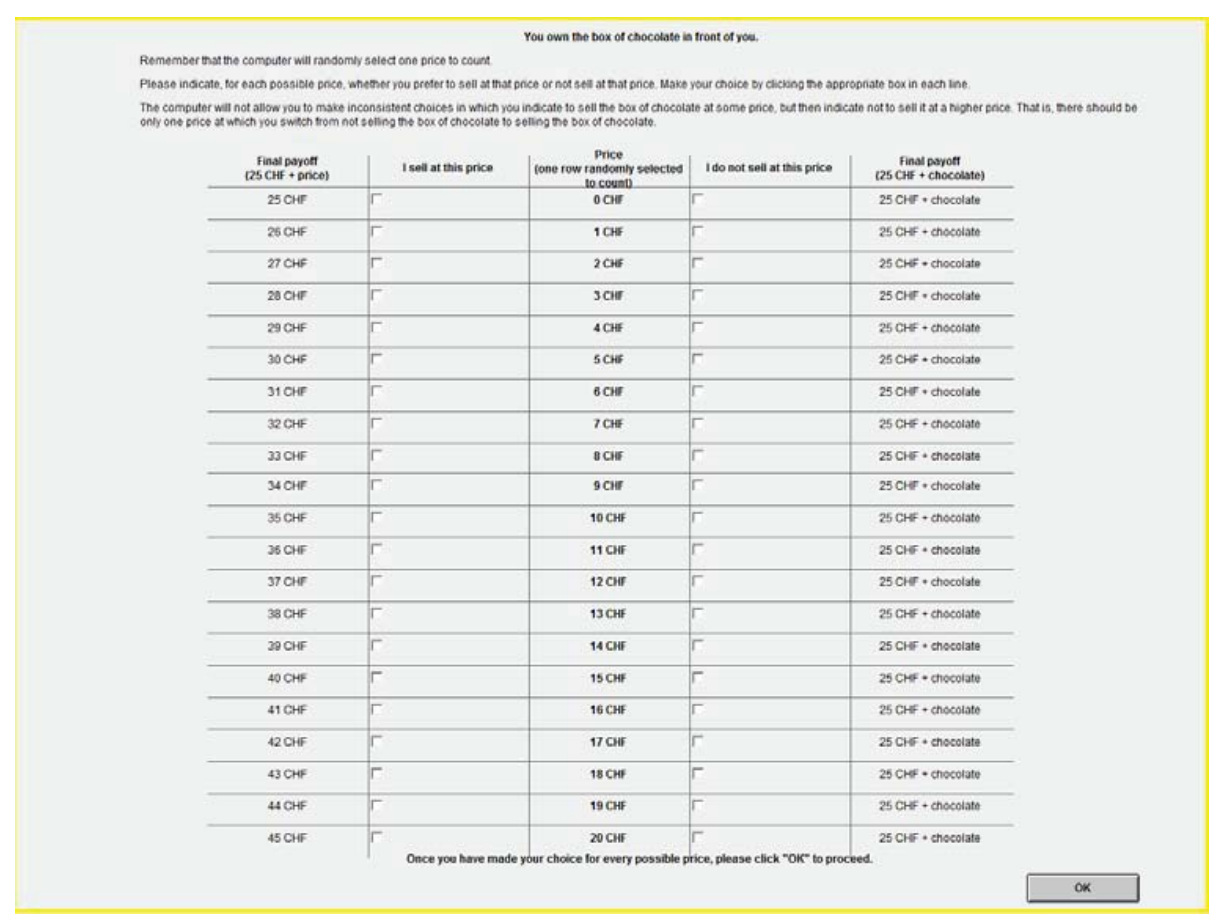

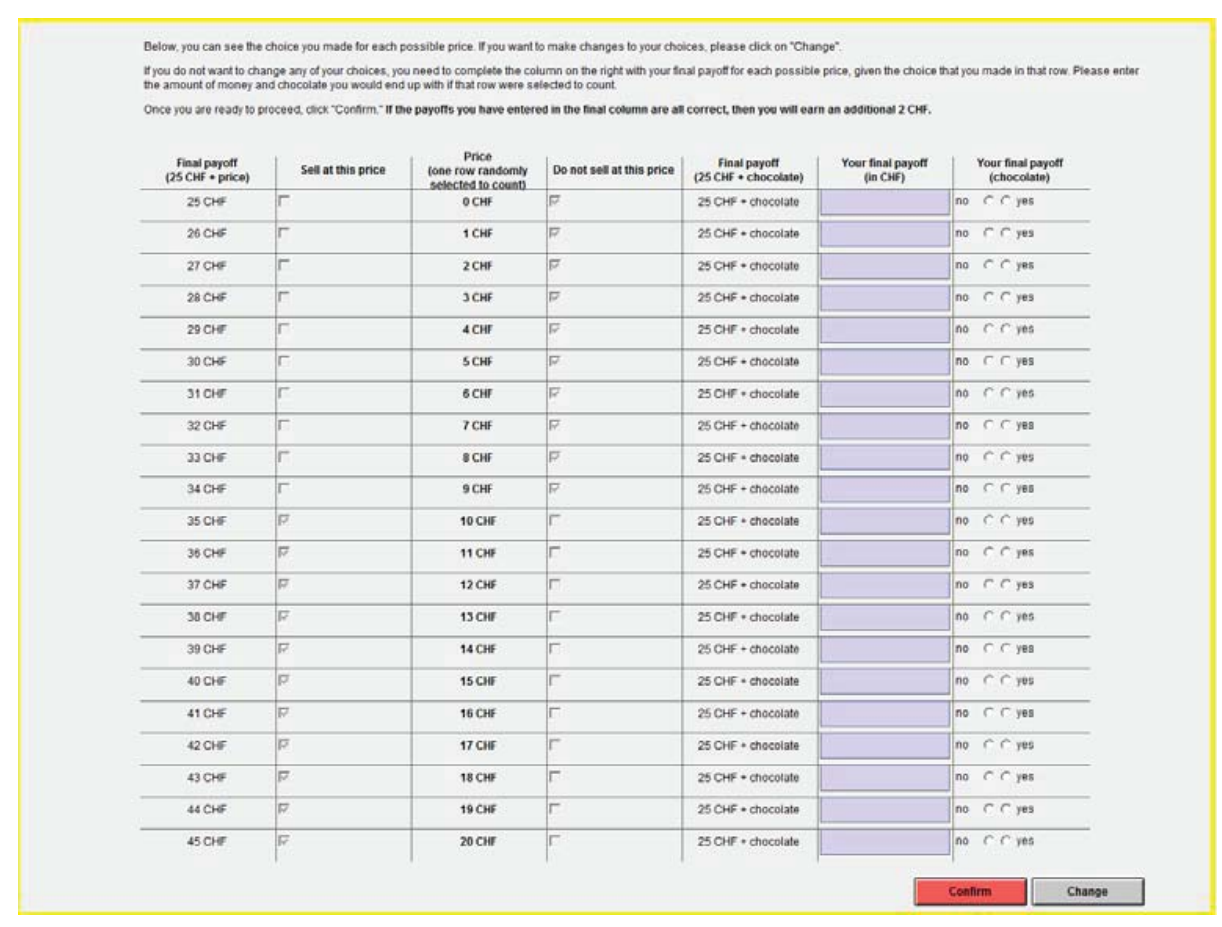

